\title{
Competitividade e Sustentabilidade de um Cluster de Turismo: uma Proposta de Modelo Sistêmico de Medida do Impacto do Turismo no Desenvolvimento Local
}

\author{
Sieglinde Kindl da Cunha \\ João Carlos da Cunha
}

\begin{abstract}
RESUMO
Este artigo apresenta uma proposta de medida de impactos de um cluster turístico no desenvolvimento local, com o objetivo de avaliar, de forma sistêmica, o grau de interação, competitividade e sustentabilidade do cluster turístico e seus impactos em termos econômicos, sociais e ambientais. $\mathrm{O}$ modelo tem como fundamentação teórica o conceito e a tipologia de cluster, adaptando e integrando os conceitos de competitividade sistêmica e de sustentabilidade nas dimensões econômicas, sociais, culturais, ambientais e políticas. O modelo proposto apresenta uma visão holística, multidisciplinar e multissetorial do desenvolvimento local, resgatando, por meio da abordagem sistêmica, os conceitos de competitividade, eqüidade social e sustentabilidade. Os resultados possibilitam orientar estrategicamente agentes responsáveis pelas políticas públicas do setor de turismo, bem como as empresas e instituições públicas e privadas em suas estratégias de competitividade, competição, cooperação e sustentabilidade.
\end{abstract}

Palavras-chave: turismo; cluster; desenvolvimento local; competitividade; sustentabilidade.

\begin{abstract}
This article proposes a model to measure tourism cluster impact on local development with a view to assessing tourism cluster interaction, competitiveness and sustainability impacts on the economy, society and the environment. The theoretical basis for this model is founded on cluster concept and typology (MYTELKA; FARINELLI, 2004; PORTER, 1999), adapting and integrating the systemic competitiveness and sustainability concepts (ALTENBURG et al., 1998) within economic, social, cultural, environmental and political dimensions (RUSCHMANN, 2001). The proposed model shows a holistic, multidisciplinary and multi-sector view of local development brought back through a systemic approach to the concepts of competitiveness, social equity and sustainability. Its results make possible strategic guidance to agents responsible for public sector tourism policies, as well as the strategies for competitiveness, competition, cooperation and sustainability in private companies and institutions.
\end{abstract}

Key words: tourism; cluster; local development; competitiveness; sustainability: 


\section{INTRODUÇÃO}

O turismo nos últimos 50 anos vem-se destacando como uma das atividades com maior potencial de expansão em escala mundial. A partir dos anos 80 , a aceleração do processo de internacionalização e de abertura das economias nacionais provoca verdadeira explosão na atividade de turismo, sendo apontado como o segundo setor mais globalizado, perdendo somente para o setor financeiro (SILVEIRA, 2002). Os avanços tecnológicos do sistema de transporte e comunicações, com melhorias significativas da qualidade, redução do tempo e dos custos das viagens, o aumento do número de viagens de negócios e as conquistas sociais tais como: férias remuneradas e finais de semana prolongados têm atuado como aceleradores do processo de crescimento e globalização do turismo.

Devido ao seu potencial de crescimento e por ser produto que somente pode ser consumido in loco, o turismo tem importante e estratégico papel no desenvolvimento local. De acordo com a Organização Mundial do Turismo (OMT, 2004), o turismo é uma atividade que favorece o desenvolvimento local; gera emprego, aumento de renda dos trabalhadores, investimentos de capital em novas oportunidades de negócio, cria novas organizações, incluindo pequenas e médias empresas, além de outras vantagens. O desenvolvimento do turismo pode trazer também muitos impactos negativos na sustentabilidade econômica, social e ambiental da comunidade, tais como a poluição sonora, da água e visual, invasão de áreas protegidas, especulação imobiliária, crescimento da violência, perda da identidade e cultura local, alterações de padrão de consumo, entre outros.

A direção e a intensidade do impacto (positivo, negativo ou ambos), dependem da forma como os atores sociais se organizam e interagem para atingir objetivos comuns de melhoria de qualidade de vida, aumento da competitividade e poder de atração turística, assim como a preservação e proteção do ambiente natural e cultural.

Mesmo com o potencial de desenvolvimento do turismo em todos os níveis, existem poucos estudos a respeito de modelos de avaliação do impacto do turismo no desenvolvimento local. Os mais conhecidos modelos de mensuração do impacto são aqueles que avaliam o impacto sobre o emprego e renda; mas são poucos que avaliam, de forma sistêmica, a influência positiva e negativa que o turismo tem sobre uma região e sua população, em termos econômicos, socioculturais e ambientais.

A atividade de turismo, apesar de sua característica fortemente relacionada com o espaço físico (território), e ao espaço abstrato (interação dos atores sociais locais), tem grande relação com a preservação da natureza, uma vez que esta deve ser utilizada sem ser destruída.

"Enquanto a indústria destrói para produzir, o turismo deve preservar para produzir. A harmonização do turismo com o ambiente é uma mudança na forma de pensar, uma inovação conceitual para superar uma contradição que facilmente acontece entre o turismo destrutivo e a proteção de um turismo que deve ser preservado" (RUSCHMANN, 2001, p. 69).

O conceito de cluster é apropriado às características específicas das atividades de turismo. O produto turístico interage com a base local (física e atores sociais), permitindo ações conjuntas de negócios inter-relacionados, com grande potencial para criação de conglomerados. Além disso, outras características definem o potencial das atividades de turismo: a complementaridade e interdependência dos componentes do conglomerado turístico ocorrem através da interação e organização dos atores locais; a necessária interação da cultura, economia e ambiente permite intervenções e ações que ocorrem de forma sistêmica e o poder de atração depende do potencial de diferenciação do produto turístico e de seus serviços de apoio.

A hipótese central para formulação do modelo de impacto do turismo no desenvolvimento local, proposta neste artigo, é esta: a atividade turística constitui uma das principais fontes de desenvolvimento regional sustentável, com efeitos positivos sobre a geração de emprego, renda e qualidade de vida. No entanto o desenvolvimento sustentável requer ações para reduzir as pressões 
destrutivas sobre o ambiente, sobre a integridade cultural e qualidade de vida da população local. As ações direcionadas para o desenvolvimento do turismo sustentável necessitam apoiar-se em estudos que avaliem seus impactos positivos e negativos, dimensionando, de forma sistêmica, as variáveis econômicas, sociocultural e ambiental.

Este artigo pretende apresentar uma proposta para medir o impacto do turismo no desenvolvimento local, utilizando a análise de cluster. Um modelo sistêmico é proposto para medir as variáveis que favorecem as complementaridades e interações dos atores sociais locais, a competitividade de um cluster de turismo em seus aspectos meta, meso, macro e microeconômico e seu potencial de sustentabilidade econômico, social, cultural e ambiental.

Para atender a este objetivo, o artigo será desenvolvido com enfoque nas questões explicitadas a seguir. Inicialmente, apresenta-se o conceito de desenvolvimento local, enfocando as características específicas da atividade do turismo e os principais impactos da atividade de turismo no desenvolvimento local. A seguir destaca-se a relevância do referencial conceitual de clusters (PORTER, 1999) e a tendência à clusterização das atividades turísticas. A partir deste referencial, sublinham-se as relações complementares entre a oferta de produtos turísticos e as estratégias competitivas e cooperativas desenvolvidas entre os atores sociais, sua aderência explicativa às variáveis que compõem o cluster de turismo (complementaridade, cooperação e competição) e a sua capacidade de atuar no sentido de abrandar ou aprofundar a tendência de concentração setorial, social e espacial da produção e apropriação. A seção 2 destaca a relevância de abordar a sustentabilidade ambiental, cultural, social e econômica nas avaliações de impacto das atividades de turismo no desenvolvimento local. A seção 3 apresenta o referencial teórico da competitividade em um enfoque sistêmico, abordando os conceitos e as variáveis econômicas nos níveis meta, macro, meso e micro. Em seguida, na seção 4, são apresentados e criticados alguns modelos para avaliar o impacto do turismo no desenvolvimento local. A seção 5 apresenta o modelo alternativo para avaliar, de forma sistêmica, o impacto do cluster em termos econômicos socioculturais e ambientais, as etapas para a aplicação do modelo, os principais resultados e produtos obtidos e as vantagens e limites do modelo proposto. Por último, serão apresentadas as principais conclusões.

\section{CLUSTER Turístico e a BASE Local}

A interação do consumo do produto turístico com a base local é uma das principais características dessa atividade, o que mostra seu papel fundamental nas estratégias de desenvolvimento local. $\mathrm{Na}$ maioria das atividades econômicas, é o produto que vai até o consumidor, mas no turismo é oposto, é o consumidor que busca pelo serviço. Devido a esta característica, a atividade do turismo tem forte impacto no desenvolvimento local. Nesta perspectiva, a atividade de turismo e o desenvolvimento local se fundem, quando as características regionais, sociais, culturais e ambientais são respeitadas.

\section{O Conceito de Desenvolvimento Local}

A idéia central de desenvolvimento envolve uma rede de conceitos associados à evolução, inclusão, participação, solidariedade, produção e competitividade que se reforçam mutuamente ou se opõem frontalmente aos movimentos de concentração, competição, exclusão, pobreza, desequilíbrio, entre outros.

A evolução e a interação são os pontos focais do conceito de desenvolvimento, em que um conjunto coordenado de processos participativos permite progredir de modo contínuo no debate e no reforço de capacidades de planejamento e mobilização de recursos econômicos, sociais, ambientais da sociedade, a curto e longo prazo, cujo alcance é devido às estratégias articuladas, quando possível e, em caso contrário, depende de arbitragem e conciliação (OCDE, 2001). 
O conceito de desenvolvimento local envolve mais duas idéias complementares que se associam ao território. Uma se refere ao espaço concreto e delimitado e vincula-se à idéia de constância e inércia e pode ser identificado como área delimitada: município, microrregião etc. Outra é o espaço abstrato das relações sociais e indica movimento e interação dos grupos sociais que se articulam ou se opõem em torno de interesses comuns (FISCHER, 2002). A idéia de movimento e interação é observada na medida em que o território deve levar em conta a interdependência da natureza com o seu uso, que inclui a ação humana, isto é, o trabalho e a política (SANTOS, 1999).

Três elementos do desenvolvimento local se destacam a partir do turismo: a sociedade, o ambiente e a economia, que são integrados e se reforçam mutuamente, em contexto em que a diversidade social e cultural e a diferenciação produtiva devem ser utilizadas como recursos potenciadores de transformações e de desenvolvimento local.

O turismo possui algumas características que o diferenciam de outras atividades produtivas: é um produto que só pode ser consumido in loco, estimula o desenvolvimento de outras atividades econômicas (entretenimento, comércio, transportes, meios de hospedagem, agências de viagens, artesanato, serviços de apoio); estimula o desenvolvimento da infra-estrutura (estradas, aeroportos, saneamento, energia etc.); depende da sustentabilidade cultural e ambiental e tem forte efeito indutor na geração de renda e emprego local.

\section{O Conceito de ClusterTurístico}

O conceito de cluster se adapta às características específicas da atividade de turismo, cujo produto está vinculado à sua base local e à ação conjunta de uma aglomerado de empresas vinculadas aos produtos turístico da região.

Porter (1999, p. 211-212) define aglomeração como:

...é um agrupamento geograficamente concentrado de empresas inter-relacionadas e instituições correlatas numa determinada área, vinculadas por elementos comuns e complementares. O escopo geográfico varia de uma única cidade ou estado para todo um país ou mesmo uma rede de países vizinhos. Os aglomerados assumem diversas formas, dependendo de sua profundidade e sofisticação, mas a maioria inclui empresas de produtos ou serviços finais, fornecedores de insumos especializados, componentes, equipamentos e serviços, instituições financeiras e empresas em setores correlatos. Os aglomerados geralmente também incluem empresas em setores a jusante (ou seja, distribuidores ou clientes) fabricantes de produtos complementares, fornecedores de infra-estrutura, instituições governamentais e outras, dedicadas ao treinamento especializado, educação, informação, pesquisa e suporte técnico (como universidades, centros de altos estudos e prestadores de serviços de treinamento vocacional), e agências de normatização. Os órgãos governamentais com influência significativa sobre o aglomerado seriam umas de suas partes integrantes. Finalmente, muitos aglomerados incluem associações comerciai e outras entidades associativas do setor privado, que apóiam seus participantes.

Em clusters, outras características são relevantes: troca de informações entre firmas, instituições e indivíduos inseridos no cluster, existência de uma diversificada infra-estrutura institucional de apoio às atividades desenvolvidas, presença de uma identidade sociocultural, vantagens competitivas coletivas, desenvolvimento de especialização coletiva, implementação de ações estratégicas entre os agentes, organização simultânea de relações de concorrência e cooperação entre os agentes.

Para Zacarelli (2004, p. 200), um cluster completo deve incluir outras características relacionadas à tecnologia, assim como a competitividade, sustentabilidade ambiental e cultural, qualidade de vida e sinergia, como resultado de relações sistêmicas. Além das variáveis sugeridas, Porter adiciona: o hábito de reutilização de materiais recicláveis; intensa competição entre os atores do cluster e destes com outros clusters; padrão tecnológico similar entre as empresa; cultura social adaptada às atividades do cluster; alta relação e sinergia entre os agentes e amplos benefícios relativos à qualidade de vida.

O conceito de cluster desenvolvido nesse artigo é similar aos conceitos desenvolvidos por Porter e Zacarelli, uma vez que as variáveis de atratividade, competitividade, sustentabilidade econômica e 
cultural e qualidade de vida são aquelas que fazem com que um cluster de turismo se diferencie dos demais tipos de cluster.

Conceito de cluster turístico (adaptado por Montfort do conceito de Aglomerações de Porter):

“... conjunto complexo de diferentes elementos, entre os quais se encontram os serviços prestados por empresas ou negócios turísticos (alojamento, restauração, agência de viagens, parques - aquáticos, temáticos etc.); a riqueza que proporciona a experiência das férias de um turista; o encontro multidimensional entre empresas e indústrias relacionadas; as infra-estruturas de comunicação e transporte; as atividades complementares (dotação comercial, tradição em feiras etc.); os serviços de apoio (formação e informação etc.); e os recursos naturais e as políticas institucionais" (MONFORT, 2000, p. 46).

Enquanto Monfort destaca as características e os componentes de um cluster, Beni, em artigo publicado no ano de 2003, define cluster, enfatizando a articulação entre os agentes e a cooperação através da formação de redes de empresas:

"Cluster turístico é o conjunto de atrativos com destacado diferencial turístico, concentrado num espaço geográfico delimitado dotado de equipamentos e serviços de qualidade, de eficiência coletiva, de coesão social e política, de articulação da cadeia produtiva e de cultura associativa, e com excelência gerencial em redes de empresas que geram vantagens estratégicas comparativas e competitivas" (BENI, 2003, p. 74).

As relações entre empresas e instituições em um cluster turístico podem ser compreendidas em duas vertentes (RODRIGUES, 2001, p. 307).

- Horizontal - pela formação de alianças estratégicas, cujos acordos podem ser de dois tipos, de um lado os acordos entre empresas que se dedicam à mesma atividade principal, ou seja, entre empresas que se dedicam ao alojamento, à animação, ao transporte ou à restauração (alimentação); de outro lado, os acordos entre empresas que se dedicam em satisfazer ao mesmo grupo de clientes, mas proporcionando-lhes distintos componentes do produto (serviços turísticos).

Vertical - através da formação de redes estratégicas, onde ocorre o estabelecimento de uma relação fornecedor-cliente unilateral entre os sócios, de tal modo que as atividades objeto do acordo são realizadas por uma das partes, que cede o seu output a outra em troca de uma contraprestação.

Neste artigo desenvolvemos o conceito de que um cluster turístico está associado a um conjunto de empresas e instituições vinculadas à oferta de um produto ou um conjunto de produtos turísticos. Estas empresas e instituições estão espacialmente concentradas e estabelecem entre si relações verticais (dentro da cadeia produtiva do turismo) e horizontais (envolvendo o intercâmbio de fatores, competências e informações entre agentes similares vinculados a oferta do produto turístico). Apresentam uma conformação interna que geralmente inclui:

a) Conjunto de atrações turísticas que exerçam atração sobre os não residentes.

b) Concentração de empresas de serviços turísticos: restaurantes, meios de hospedagem, serviços de transporte, artesanatos, agências de viagens etc.

c) Setores de apoio à prestação de serviços turísticos.

d) Infra-estrutura apropriada e de baixo custo: estradas, energia, saneamento, serviços de saúde etc.

e) Empresas ou instituições que fornecem qualificações especializadas, informações, capital financeiro.

f) Agentes internos organizados em associações de classe.

g) Agências governamentais e outros órgãos reguladores que exerçam influência sobre a aglomeração turística. 
As vantagens das redes de cooperação nas atividades de turismo permitem a efetiva exploração da eficiência coletiva e/ou economias externas às empresas (cooperação empresarial, especialização produtiva do trabalho, infra-estrutura coletiva, especialização de serviços etc.) e o aumento da capacidade de negociação coletiva com fornecedores de insumos e componentes. Além dessas vantagens, as redes de cooperação facilitam o desenvolvimento de novos modelos, processos e organização da produção, troca de informações técnicas e de mercado, criação de consórcios de compra e venda de bens e serviços e campanhas conjuntas de divulgação de imagem e de marketing. "A interação e a sinergia decorrentes da atuação conjunta proporcionam vantagem competitiva superior à ação isolada de cada empresa" (NORDIN, 2003, p. 19).

Figura 1: Representação de um Cluster Turístico

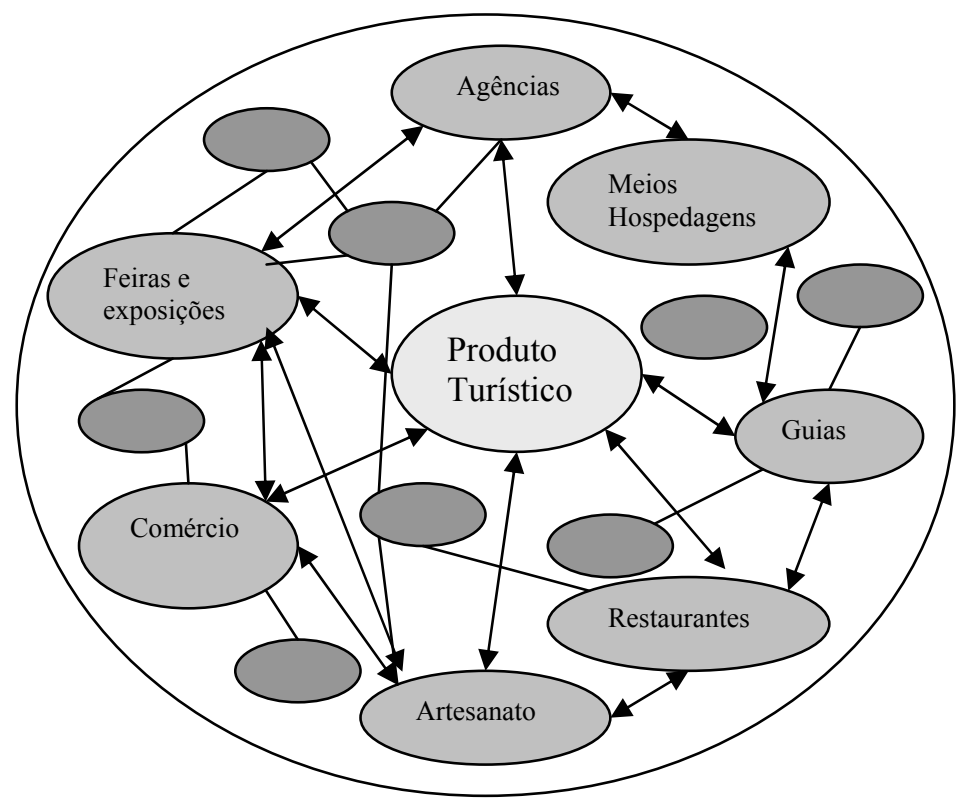

Fonte: elaborada pelos autores.

Embora a colaboração seja a base de sustentação de um cluster, a competição é exercida vigorosamente. Mesmo quando a cooperação é o elemento forte do cluster, a rivalidade é também necessária para o desenvolvimento e sobrevivência do cluster. Sem competição as empresas são fadadas a fracassar, principalmente no que se refere ao processo dinâmico das inovações.

Em função de suas características, o cluster de turismo tem sido apontado em programas de desenvolvimento local como atividade estratégica para combater as disparidades regionais e as desigualdades sociais. Porter (1999, p. 230) enfatiza que no "turismo, por exemplo, a qualidade da experiência do visitante depende não só do apelo da atração principal (como praias ou localidades históricas), mas também do conforto e do serviço dos hotéis, restaurantes, lojas de suvenires, aeroportos, outros meios de transportes e assim por diante". Como ilustra o exemplo, as partes do aglomerado são, em geral, efetivamente dependentes entre si. O mau desempenho de uma delas compromete o êxito das demais.

Nem todas as regiões oferecem as mesmas condições para o desenvolvimento do turismo. Uma região com potencial de desenvolvimento do turismo deve possuir características culturais, físiconaturais e sociais que definam sua identidade regional: infra-estrutura adequada que favoreça a acessibilidade; supra-estrutura (meios de hospedagem, restaurantes, serviços de transporte etc.) que garantam a qualidade do produto turístico; localização estratégica em relação aos pólos emissores de turistas; atrações turísticas em número suficiente para atrair turistas e viabilizar economicamente as atividades envolvidas com o turismo e estratégias de marketing turístico para divulgar uma imagem 
atrativa, diferenciada e competitiva do produto turístico (SMITH, 1989). No entanto, a sustentabilidade de um cluster turístico em termos econômicos, sociais, ambientais e culturais só ocorrerá se a exploração do produto turístico estiver embasado em políticas públicas e planejamento estratégico que definam as condições de sustentação e a sua inserção multiescalar: regional, nacional e global.

\section{SUSTENTABILIDADE DE UM CLUSTER TURístico}

O turismo causa um impacto direto que afeta tanto o sistema territorial como a produção do próprio turismo. A degradação ambiental de uma praia não significa somente a degradação do sistema territorial, mas também a afeta competitividade do turismo na região (IVARS, 2004, p. 25-26).

A sustentabilidade é um conceito fundamental no que concerne à reavaliação do papel do turismo na sociedade contemporânea. Na definição elaborada pela Organização Mundial do Turismo (OMT):

“O turismo sustentável é entendido como aquele que satisfaz as necessidades presentes dos turistas, ao mesmo tempo que preserva as regiões de destino e incrementa novas oportunidades para o futuro. Ele deve ser concebido de modo a conduzir à gestão de todos os recursos existentes, tanto do ponto de vista da satisfação das necessidades econômicas, sociais e estéticas, quanto da manutenção da integridade cultural, dos processos ecológicos essenciais, da diversidade biológica e dos sistemas de suporte à vida" (OMT, 1998, p. 21).

O modelo de desenvolvimento local com base no turismo sustentável envolve relações bastante complexas e só poderá ser concretizado se forem levadas em conta as diversas dimensões da realidade de uma dada região ou território. Ruschmann (2001) destaca que é preciso considerar as seguintes dimensões para se buscar a sustentabilidade no planejamento do desenvolvimento local.

- Sustentabilidade ecológica e ambiental: refere-se à base física do processo de desenvolvimento e objetiva a conservação e o uso racional de estoque de recursos naturais incorporados às atividades turísticas, além da capacidade de suporte dos ecossistemas associados em absorver ou recuperar-se das agressões antrópicas.

- Sustentabilidade econômica: busca do crescimento/desenvolvimento econômico através da alocação e da gestão eficiente dos recursos, e da realização de constantes investimentos públicos e privados, de maneira a garantir não apenas a rentabilidade empresarial de caráter microeconômico, mas a eficácia econômica em termos sociais no presente e no futuro.

- Sustentabilidade sociocultural: refere-se à necessidade de manter a diversidade cultural, valores e práticas existentes em uma região e a construção da cidadania e da integração social plena dos indivíduos a uma cultura de direitos e deveres.

Sustentabilidade Política Institucional: fortalecimento dos mecanismos democráticos de formulação e implementação de políticas públicas, e o fortalecimento de arranjos institucionais e organismos de representação político-social, cujo desenho e aparato já levem em conta os critérios de sustentabilidade.

\section{COMPETITIVIDADE SistêMICA DE UM ClusteR TURístico}

Os agentes de um cluster turístico se movem por densas relações de interação, cooperação e competição: em nível de firmas (fornecedores, clientes e competidores); de mesoinstituições (instituições públicas e privadas e representantes da sociedade civil); de macroinstituições (estratégias 
e políticas macroeconômicas); e de estruturas socioculturais (habilidades dos atores sociais em formular visões e estratégias de desenvolvimento sustentável).

A união do território, instituições e empreendimentos e suas respectivas vantagens competitivas é o que constituirá a competitividade de um cluster de turismo.

“(...) competitividade do turismo é a capacidade dos agentes de interferir nas atividades do turismo de interferir em um país, região ou zona turística, para atingir suas metas acima da média do setor de uma forma sustentada e sustentável, o que pode ser alcançado por concessões lucrativamente financiadas acima da média do setor, e por ganhos sociais e ambientais como consequência de intervenções de organizações e instituições públicas, além de obter a máxima satisfação do turista. Assim, o objetivo último da competitividade é atender da melhor forma possível às expectativas de todos os agentes que participam na atividade de turismo" (Silva, 2004, p. 374).

A competitividade sistêmica de um cluster (ALTENBURG et al., 1998) compreende quatro níveis de relações em rede, como se detalhe em seguida.

- Meta - engloba fatores socioculturais que definem a capacidade de articulação dos atores sociais e sua habilidade de formulação de estratégias e políticas de interesses da sociedade local.

- Macro - estratégias e estabilidade da estrutura macroeconômica, definidas pelas políticas fiscal, monetária, cambial, comercial e de competição.

- Meso - estruturas de suporte que facilitam a interação e cooperação de firmas (fornecedores, clientes e concorrentes); a interação e cooperação com instituições de $\mathrm{P} \& \mathrm{D}$, de instituições de suporte ao financiamento, de instituições de apoio e disseminação, como marketing, exportações, feiras etc.; de instituições de formação e treinamento da mão-de-obra, e da existência de infra-estrutura: transporte, comunicação, energia.

- Micro - capacidade da firma, ou de uma rede de firmas para se manterem competitivas, oferecendo bens e serviços que otimizem a relação custo-eficiência, a qualidade, a variedade e a habilidade de reação às novas oportunidades e mudanças de mercado. 
Figura 1: Níveis de Competitividade Sistêmica de um Cluster Turístico

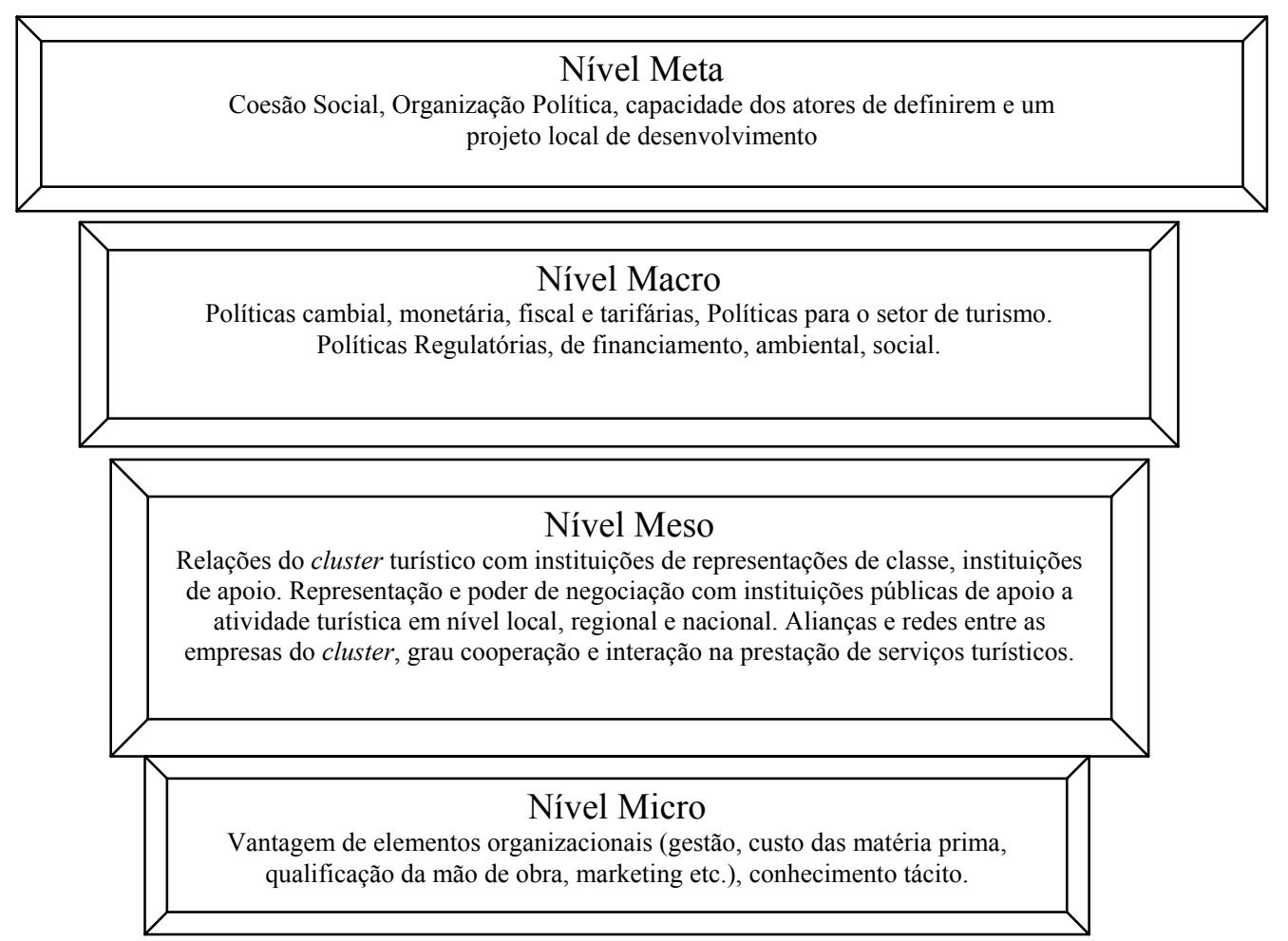

Fonte: elaborado pelos autores e adaptado de Altenburg et al. (1998).

\section{Metodologias Mais Comumente Utilizadas para Medir o Impacto do Turismo No Desenvolvimento Local}

A Organização das Nações Unidas - ONU, desde 1950, mantém um sistema padrão de medição da atividade econômica, através de um sistema consolidado de informações macroeconômicas, denominado Sistema de Contas Nacionais - SCN, utilizado hoje por todos os países membros da ONU. O SCN padroniza conceitos, metodologias de cálculo, estatísticas e sistemas de informações, permitindo desta forma a comparabilidade temporal dos resultados econômicos entre países, regiões e setores. No entanto este sistema de informação é muito agregado para uma análise setorial de atividades específicas, tais como turismo, saúde, educação, agroindústria e outros segmentos econômicos que envolvem atividades multissetoriais.

A Organização Mundial do Turismo - OMT, na conferência realizada em Otawa em 1991, propõe um Sistema de Contas específico para a atividade de turismo, denominado Contas Satélites do Turismo - CST, compatíveis com os conceitos, referencial teórico e método de mensuração do Sistema de Contas Nacionais. Alguns países, incluindo o Brasil, estão estruturando as CST. Estas informações, embora estratégicas para o planejamento em nível nacional, não possuem ainda um nível de desagregação em nível regional nem uma série temporal que possibilite sua utilização para o planejamento do desenvolvimento local. Desta forma, existe uma lacuna em termos de informações e metodologias de avaliação de impacto do turismo no desenvolvimento local.

De acordo com Silva (2004, p. 267), o turismo é um fenômeno definido do ponto de vista da demanda, apesar de que a maioria das classificações econômicas de atividades são estabelecidas do 
ponto de vista da oferta de produtos e serviços e da caracterização dos processos de produção. Como resultado, algumas adaptações dessas classificações são necessárias para descrever e medir, de forma adequada e útil, a incidência econômica do turismo. A estas dificuldades metodológicas deve ser adicionado o fato de que até hoje a classificação do turismo, do ponto de vista da demanda, tem sido raro. É difícil, portanto, identificar precisamente um critério estatístico que pode ser utilizado em uma base universal.

Paralelamente a OMT vem desenvolvendo metodologias e instrumentos com objetivo de criar um sistema de indicadores ambientais para a sustentabilidade do turismo. No entanto são poucos os países e regiões que produzem esses indicadores de forma sistemática, padronizada, desagregada e capaz de medir os efeitos positivos e negativos, em termos ambientais, sociais, econômicos e culturais.

Grandes esforços vêm sendo realizados, em termos de desenvolvimento de técnicas de planejamento. As metodologias de planejamento turístico mais conhecidas e disseminadas são as relacionadas a inventário e projetos de implantação de pólos turísticos: inventário dos recursos turísticos, zoneamento turístico, implantação de pólos turísticos, integração entre produto turístico e infra-estrutura, instalação de circuitos e roteiros turísticos, distribuição espacial da demanda, análise de custo-benefício, entre outros.

Pouco se avançou em termos de desenvolvimento de metodologias de avaliação quantitativa e/ou qualitativa de impacto do turismo. Os modelos mais comuns de medidas de impactos são os modelos quantitativos de impacto econômico, destacando-se entre estes o modelo de multiplicador de emprego e renda keynesiano e os modelos que medem o impacto do turismo na Balança de Pagamentos de um país ou região. Entre os modelos de medida de impactos sociais, destaca-se o Índice de Desenvolvimento Humano - IDH, proposto e desenvolvido pela ONU, que tem por objetivos medir o bem-estar e a qualidade de vida da população local.

Outra metodologia utilizada, em termos de planejamento e ordenamento territorial de regiões turísticas, é Capacidade de Carga. Esta metodologia mede o nível de uso que um espaço de destino pode suportar, sem causar efeitos negativos nos recursos naturais, na comunidade e na economia e sem que haja redução da satisfação dos turistas.

A partir do início da década de 90 tem sido crescente a preocupação em avaliar o papel desempenhado pelo turismo, enquanto estratégia de promoção e desenvolvimento dos territórios. $\mathrm{O}$ crescimento desordenado do turismo pode causar vários tipos de problemas às populações locais: agressão ao meio ambiente, destruição de culturas e do patrimônio histórico e até mesmo destruição do potencial da atividade turística local.

Assim, o planejamento e a avaliação de planos de desenvolvimento do turismo passaram a fazer parte da agenda da OMT com a elaboração em 1995 da "Agenda 21 para a Indústria de Viagens e Turismo". O objetivo principal da agenda é estabelecer dispositivos e procedimentos que levem as instituições governamentais, organizações não-governamentais e representantes do setor de viagens e turismo a colocar o desenvolvimento sustentável no centro das decisões políticas e dos processos de planejamento e gestão.

Paralelamente a esta iniciativa, novos critérios e metodologias vêm sendo propostos, em substituição aos procedimentos técnicos atualmente vigentes, de avaliação de impacto do turismo no desenvolvimento local. As instituições internacionais vinculadas à atividade de turismo, assim como as instituições de planejamento dos países que têm seu potencial de desenvolvimento vinculado ao turismo, têm direcionado esforços para o desenvolvimento de novas metodologias para avaliar, de forma sistêmica e integrada, as relações entre os fatores econômicos, socioculturais, ambientais e político-institucionais. Com vista a este objetivo apresenta-se a seguir uma proposta metodológica de avaliação do impacto do turismo no desenvolvimento local. 


\section{Avaliação do Impacto do Turismo no Desenvolvimento local: Proposta de Um MODELO SISTÊMICO}

Os parâmetros teóricos e modelos conceituais de avaliação do impacto do turismo no desenvolvimento local mostram lacunas que só recentemente têm sido preenchidas por pesquisadores, universidades e instituições de pesquisa. A maior parte das pesquisas tem priorizado a escala microeconômica e mais recentemente a prioridade tem mudado para a sustentabilidade ambiental.

Neste capítulo apresenta-se uma proposta alternativa de metodologia de avaliação de impacto da atividade de turismo sobre o desenvolvimento local. $\mathrm{O}$ modelo utiliza como fundamentação o conceito de cluster turístico e tem por objetivo avaliar o impacto que a oferta de um produto ou conjunto de produtos turístico tem sobre a competitividade e sustentabilidade econômica, social, ambiental, cultural de uma região. O modelo tem como fundamentação teórica o conceito e a tipologia (PORTER, 1999) e (MYTELKA; FARINELLI 2000, p. 4), adaptando e integrando os conceitos de competitividade sistêmica (ALTENBURG et al., 1998), e sustentabilidade nas dimensões econômicas, sociais, culturais, ambientais e políticas (RUSCHMANN, 2001), como proposta de medida de impacto do turismo no desenvolvimento local.

\section{Apresentação Esquemática do Modelo Sistêmico de Medida do Impacto do Turismo no Desenvolvimento Local}

Visando possibilitar análises comparativas, o método a ser utilizado deve ter caráter genérico. Nesse sentido, considera-se um conjunto de atores que compõe o cluster turístico e suas relações, os fatores indutores da competitividade nos diferentes níveis (meta, macro, meso e micro) e os fatores indutores da sustentabilidade (econômica, social, ambiental, cultural e político-institucional) que podem ser aplicados a qualquer tipologia de Cluster turístico e, portanto, podem ser utilizados para comparações regionais e temporais.

Da mesma forma, no tocante à análise das inter-relações dos atores com os fatores indutores da competitividade e da sustentabilidade de cada cluster, propõe-se a utilização de técnicas que podem ser aplicadas em diferentes situações (CUNHA et al., 2004). 


\section{Figura 3: Modelo de Impacto do Turismo no Desenvolvimento Local - Competitividade e Sustentabilidade}

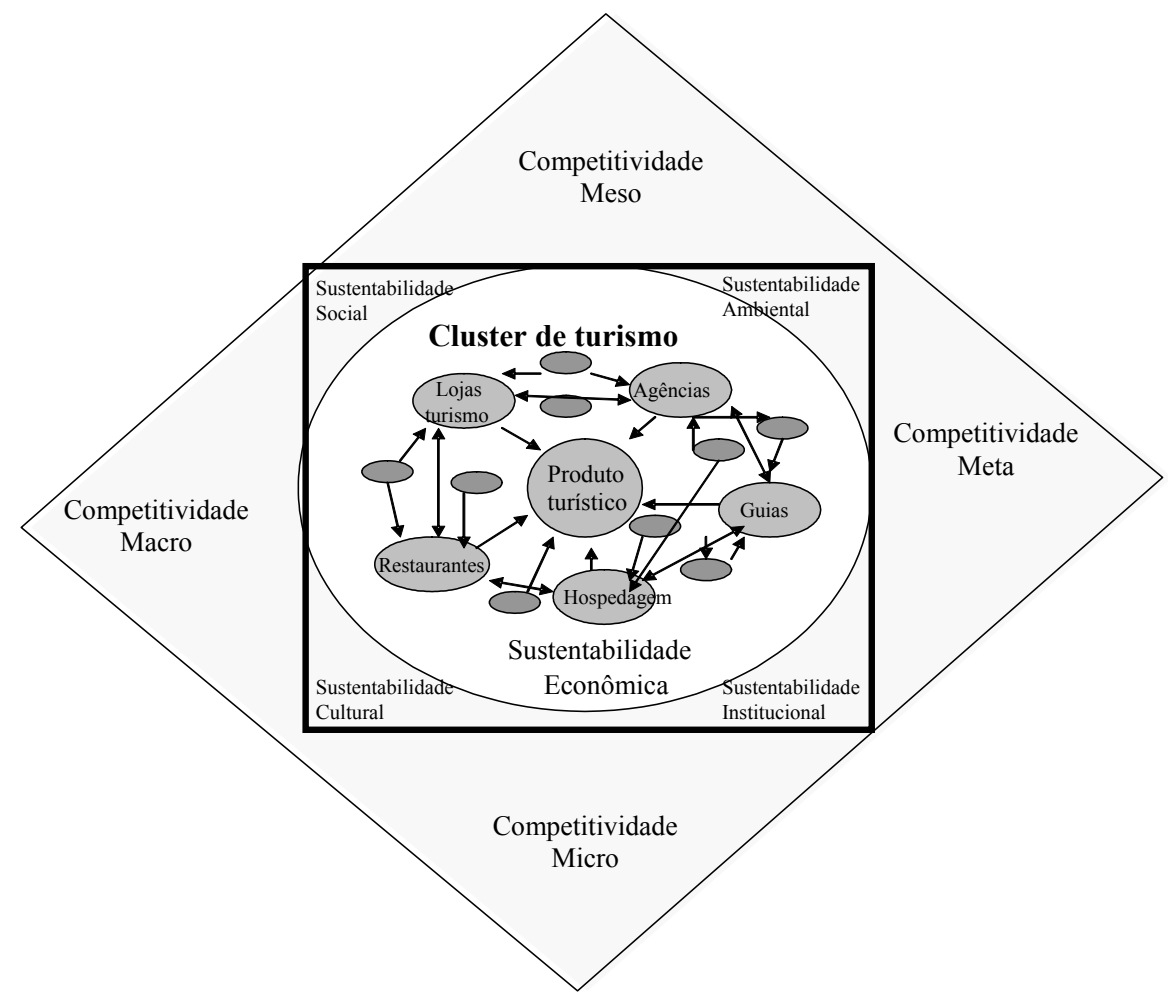

Metodologia desenvolvida pelo autor.

\section{Etapas de Desenvolvimento e Aplicação do Método}

$1^{a}$ etapa: Identificação e caracterização de um cluster turístico.

. O turismo ou produto turístico e seu potencial para a diversidade.

. Conjunto de empreendimentos que potencialmente compõe a estrutura turística.

- Supra-estrutura de suporte aos turísticos oferecidos: restaurantes, hotéis, agências de viagens, comércio, artesanato, serviço de suporte ao turista etc.

. Infra-estrutura de suporte: estradas, saneamento, energia, comunicação etc.

Serviços de suporte institucional: instituições governamentais, associações de empresas e trabalhadores, centros de treinamento de trabalhadores, instituições de financiamento.

A partir da identificação dos componentes e suas relações e da delimitação espacial do cluster de turismo, sugere-se que sejam seguidos os seguintes estágios para identificar suas características e diversidades.

Diagnóstico do setor no nível interno e externo.

- Identificação do objetivo geral do cluster, o qual genericamente é melhorar a competitividade e a sustentabilidade.

. Estratégias e ações desenhadas para atingir os objetivos do cluster. 
$2^{\mathbf{a}}$ etapa: Identificação dos atores principais ou elementos constitutivos do cluster, organizados em rede, detalhados como segue.

. Identificação e avaliação dos fatores indutores da competitividade nos diferentes níveis: meta, macro, meso e micro.

. Identificação e avaliação dos fatores indutores da sustentabilidade nos diferentes níveis: econômica, social, ambiental, cultural e político-institucional.

- Identificação e análise das inter-relações dos fatores indutores da competitividade e da sustentabilidade com os principais atores do cluster.

. Identificação e análise dos perfis institucionais que caracterizam os atores do cluster, organizados num quadro de elementos e papéis de cada instituição.

$3^{\mathbf{a}}$ etapa: Pesquisa de campo e elaboração da matriz de impactos cruzados. Consiste na montagem de matriz de dupla entrada que relaciona em um dos eixos os agentes e atores locais e, no outro, os subfatores e variáveis que têm algum impacto no desenvolvimento local, assim detalhados:

- cada fator indutor da competitividade e sustentabilidade é decomposto numa série de subfatores e variáveis, aos quais é atribuído um peso relativo, considerando o seu grau de influência sobre o processo de desenvolvimento local;

- a intensidade do impacto dos fatores e subfatores e variáveis é avaliada mediante a atribuição de notas, realizadas em entrevistas com os atores componentes do cluster (empresas, instituições publicas e privadas e representantes da comunidade);

- cada entrevistado julgará que um determinado subfator ou variável influencia o desenvolvimento local de forma muito favorável $(+2)$, de forma favorável $(+1)$, de forma neutra $(0)$, de forma desfavorável (-1) ou de forma muito desfavorável (-2);

- a nota atribuída será ponderada por um peso relativo previamente atribuído a cada sub-fator;

- o somatório das notas ponderadas atribuídas a cada um dos subfatores resultará em notas relativas para cada fator indutor geral.

$4^{\text {a }}$ etapa: Tratamento Estatístico das Informações. Análise dos Componentes Principais.

Para selecionar e hierarquizar as variáveis com maior grau de influência na competitividade sistêmica e sustentabilidade do cluster turístico e seu impacto no desenvolvimento local, utiliza-se a técnica de análise estatística multivariada chamada Análise dos Componentes Principais. Esta técnica permite reduzir e hierarquizar as variáveis características da competitividade e sustentabilidade, em conformidade de um pequeno número de índices explicativos (componentes principais), por meio de combinações lineares das variáveis originais.

$5^{a}$ etapa: Hierarquização dos fatores indutores que influenciam positivamente ou negativamente na competitividade e sustentabilidade de um cluster turístico.

$6^{\mathbf{a}}$ etapa: Os resultados da pesquisa serão avaliados em um workshop com os atores principais do cluster. Neste workshop os resultados serão apresentados à apreciação e debate dos atores, que devem fazer sugestões para aumentar o potencial competitivo do cluster e reduzir impactos negativos sobre as dimensões econômica, social, ambiental e cultural.

$7^{\text {a }}$ etapa: Preparação do relatório final com os resultados da pesquisa.

\section{Principais Resultados e Produtos Gerados pelo Modelo}


O objetivo do modelo proposto é avaliar o impacto do turismo no desenvolvimento local, considerando o modelo conceitual de cluster adaptado às características e diversidades do setor de turismo. Três focos fundamentais são utilizados para avaliar os impactos, resultando em diferentes produtos que podem ser apresentados e utilizados separadamente, mas de forma complementar. A maior contribuição do modelo proposto é o seu enfoque sistêmico, levando em consideração e classificando as variáveis de competitividade e sustentabilidade, que influenciam no desenvolvimento local, positivamente ou negativamente.

O primeiro foco é definir, identificar e delimitar o cluster de turismo. O produto gerado por este nível de informação é de extrema importância para a análise de aglomerações. Possibilita avaliar o grau de clusterização das atividades de turismo, o grau de importância de cada ator ou agente no cluster, a intensidade das relações entre os atores, o grau de complementaridade entre as atividades internas do cluster, além das lacunas ou ausência de atividades no cluster. O Produto final desta fase é um mapeamento do cluster turístico, incluindo atores, relações e fluxos. Serão identificados também os inputs demandados externamente ao cluster, que poderão vir a ser oferecidos internamente, como opções de novos investimentos.

A competitividade do cluster de turismo observada através deste modelo híbrido de competitividade sistêmica (em níveis meta, meso, macro e micro) e os determinantes da vantagem competitiva de Porter ajudarão a identificar as fragilidades, em termos de competitividade. A identificação das fragilidades e potenciais competitivos nos diversos níveis e com os diferentes atores são instrumentos essenciais para o planejamento e definição de políticas públicas e a posição estratégica das organizações. O produto gerado a partir destas informações possibilitará a construção de uma matriz de dupla entrada que identifica e qualifica as variáveis competitivas pelos agentes e atores do cluster, através de uma escala positiva e negativa.

A base teórica do terceiro foco é o modelo de sustentabilidade, avaliado em suas dimensões econômica, social, ambiental e cultural. Será identificada a contribuição de cada ator em termos da sustentabilidade, nestes diferentes aspectos. Com esta informação será gerada a matriz de dupla entrada para identificar a contribuição de cada agente e ator em termos da sustentabilidade econômica, social, cultural e ambiental do cluster.

Finalmente, será obtido um modelo sistêmico para medir o impacto do turismo no desenvolvimento local através do método estatístico de análise dos componentes principais, o que resultará em matriz que vai classificar e quantificar a contribuição dos diferentes fatores no desenvolvimento local. Os resultados apresentados pelo modelo pode ser a base de decisões tomadas pelos dirigentes locais, sistema de planejamento e formuladores de políticas públicas, oferecendo indicadores sintéticos da sustentabilidade e competitividade do cluster turístico como um todo, assim como informações cruzadas e detalhadas das fragilidades e potencialidades do cluster.

\section{Vantagens e Limitações do Modelo}

As organizações e instituições nacionais e internacionais vinculadas ao planejamento e ao desenvolvimento da atividade de turismo têm-se preocupado com o desenvolvimento de modelos de avaliação de impacto da atividade de turismo sobre o desenvolvimento local, que ofereçam resultados ajustados à realidade e obedeçam a critérios científicos de homogeneização de conceitos e de padronização estatística, com o objetivo de permitir a comparabilidade espaciotemporal e setorial.

O modelo proposto neste artigo busca atender a esses objetivos, ao apresentar uma visão holística, multidisciplinar e multissetorial do desenvolvimento local e ao resgatar, através da abordagem sistêmica, os conceitos de competitividade, equidade social e sustentabilidade. A aplicação do modelo não exige uma base de dados preexistente e fundamenta-se em levantamento de informações primárias, que são fornecidas através de entrevistas e aplicação de formulário de pesquisa com os agentes locais, possibilitando captar a percepção dos próprios agentes do cluster. A aplicação da metodologia pode ser feita em tempo relativamente curto e com custos relativamente baixos. Além dessas, o modelo possui uma série de vantagens sobre as demais metodologias, uma vez que apresenta 
resultados que possibilitam orientar estrategicamente os agentes do sistema, tanto em termos de direcionamento de políticas públicas, como nas decisões das empresas e instituições públicas e privadas em suas estratégias de competitividade, competição, cooperação e sustentabilidade. As informações obtidas através da aplicação do modelo permitem também:

analisar de forma sistêmica os fatores econômicos, sociais, culturais, ambientais e políticoinstitucionais;

- fazer o mapeamento e o fluxo de intensidade das relações entre os agentes internos componentes do cluster turístico (relações com empresas concorrentes, fornecedores, prestadores de serviços, clientes, atividades de apoio, instituições governamentais, associações de classe, instituições de ensino e formação de mão-de-obra);

identificar e hierarquizar as relações que os agentes internos do cluster mantêm com os agentes das demais escalas regional, nacional e internacional, com a possibilidade de identificar e avaliar o grau de complementaridade e dependência externa do cluster;

- avaliar o grau de maturidade do cluster turístico e os fatores que criam obstáculos ou potenciam o desenvolvimento local (políticas de apoio, grau de coesão ou conflito entre os agentes, grau de interação, competição, difusão de conhecimento tácito, sistema de informação, infra-estrutura e supra-estrutura etc.).

Como principais limitações do modelo destaca-se o seu corte temporal e regional. O modelo é estático e a sua comparabilidade no tempo e no espaço depende da sua reaplicação. Além disso, o modelo só permite hierarquizar e não quantificar as variáveis responsáveis pela competitividade e sustentabilidade de um cluster turístico e seus impactos positivos e negativos no desenvolvimento local.

\section{CONCLUSÃO}

O turismo nos últimos 50 anos vem-se destacando como uma das atividades com maior potencial de expansão em escala mundial. Pelo seu potencial de crescimento e por ser produto que só pode ser consumido in loco, o turismo assume papel de destaque como estratégia de desenvolvimento local. Mesmo com o potencial de desenvolvimento em todas as escalas e o papel relevante na definição das políticas públicas de caráter intervencionista, pouco se avançou em termos de estudos, pesquisas e modelos de medidas de impactos que a atividade de turismo exerce no desenvolvimento local.

A expansão espacial do turismo e a crescente diversificação de sua atividade no mundo, ao mesmo tempo que geram novas oportunidades para países, regiões e comunidades, também trazem efeitos danosos: decompondo e recompondo espaços, deteriorando e enfraquecendo o ambiente, destruindo e criando relacionamentos sociais e produtivos que já existiam, quebrando a diversidade e as culturas locais e incorporando padrões e hábitos de consumo alienígenas.

Uma das responsabilidades para os agentes públicos encarregados de elaborar e implementar políticas de desenvolvimento para as atividades turísticas é implementar um modelo de desenvolvimento com competitividade, sustentabilidade e justiça social.

O foco da análise de cluster é adaptável às características das atividades de turismo, uma vez que é baseado na análise de aglomerações, complementaridades funcionais, relacionamento cooperativo e competitivo entre atores. Por outro lado, a análise de cluster tradicional não é clara, quando o objetivo é avaliar os impactos locais em termos de competitividade e sustentabilidade e justiça social. 
Este artigo pretende contribuir com um modelo de mensuração do impacto do turismo no desenvolvimento local, agregando ao modelo de análise de aglomeração de Porter os conceitos de competitividade em diferentes níveis e os conceitos de sustentabilidade ambiental, social e cultural.

Os resultados obtidos pela aplicação do modelo de mensuração de impactos são ferramentas para a reconciliação da preservação ambiental com a justiça social e conservação da cultura e diversidade, podendo contribuir desta forma para o avanço na implementação de modelos de desenvolvimento de clusters de turismo mais sustentáveis. A metodologia possibilita o diagnóstico e avaliação do cluster na busca da prevenção de impactos negativos e logrando que sejam orientados para o desenvolvimento da potencialidade que decorre da atividade turística.

O objetivo final do modelo é gerar informações que guiem estrategicamente os agentes encarregados das políticas públicas, assim como as empresas e instituições privadas em suas estratégias de competição, cooperação e sustentabilidade.

Como principal limitação do modelo destaca-se o seu corte temporal e regional, ou seja, o modelo é estático e a sua comparabilidade espaciotemporal depende da sua reaplicação.

Artigo recebido em 15.02.2005. Aprovado em 29.06.2005.

\section{REFERÊNCIAS BIBLIOGRÁFICAS}

ALtenBurG, T.; GILlegRAND, W. STAMER, J.M. Building System Competitiveness. 1. ed. Berlim: German Development Institute - GDI, 1998. p. 1-15.

BENI, M. C. Globalização do turismo: megatendências do setor e a realidade brasileira. 1. ed. São Paulo: Aleph, 2003. cap. 1 e 2.

CUNHA, S. K. et al. Grau de Clusterização da Industria de Painéis de Madeira da Região de Palmas PR In: SIMPÓSIO DE GESTÃO DA INOVAÇÃO TECNOLÓGICA. TECNOLOGIA E DESENVOLVIMENTO: DESAFIOS E CAMINHOS PARA UMA NOVA SOCIEDADE, 28., 2004, Curitiba. Anais... Curitiba: PGT/USP. 2004, p. 119-134. 1 C D ROM.

FISCHER, T. Poderes Locais, Desenvolvimento e Gestão. Introdução a uma agenda. In: FICHER, T. (org). Gestão do Desenvolvimento e Poderes Locais: marcos teóricos e avaliação. 1. ed. Salvador, BA: Casa da Qualidade, 2002. p. 12-32.

IVARS, J. A. Planificación Turística de los Espacios regionales en España. 1. ed. Madrid: Síntesis, 2004. cap. 1, p. 25-26.

MYTELKA, L. E.; FARINELLI, F. From Local Clusters to Innovation System. In: System of Innovation and Development: evidence from Brazil. 1. ed. Cheltenhan, UK, Northampton, MA, USA: Edward Elgar. 2004. Parte 1, p. 249-272.

. Local Clusters, Innovation Systems and Sustained Competitiveness In: Arranjos Produtivos Locais e as Novas Políticas de Desenvolvimento Industrial e Tecnológico. Nota Técnica n. 5. Estudos Temáticos. IE/UFRJ. Rio de Janeiro. 2000. p. 19. Disponível em: $<$ http:// www.ie.ufrj.br/gei/gil.shml>. Acesso em: 16 mar. 2002.

MONFORT M., V. M. Competitividad y factores críticos de éxito en la "hotelería de litoral": experiencia de los destinos turísticos Benidorm y Peñíscola. Tesis Doctoral - Universidad de Valência - Espanha: Biblioteca Virtual Miguel Cervantes, FITUR /IFEMA. 2000. Disponível em: $<$ http:// www.cervantes.com/fichaobra.htlm?Ret=2619>. Acesso em: 02 Sept. 2003. 
NORDIN S. Tourism Clustering and Innovation: path to economic growth and development. European Tourism research Institute. MID - Sweden University. Osternsund, Sweden, 2003. p.19. Disponível em: <http:// www.etour.se/dounload.>. Acesso em: 04 May 2004.

OCDE. Stratégies de développement durable. Paris, OCDE, 2001. p.15-33. Disponível em: $<$ http://www.oecd.org/dataoecd/34/102669958.pdf>. Acesso em: 29 Aug. 2003.

OMT. Guide for local authorities on developing sustainable tourism. A Tourism and Environment Publication. Madrid: Organización Mundial del Turism. 1998. cap. 1, p.21. Disponível em: $<$ http://www.would-tourism.org/publications/PR 1016-1.html>. Acesso em: 2004.

PORTER, M. E. Competição. 2. ed. Rio de Janeiro: Campus, 1999. cap.7, p. 209-304.

RODRIGUES, A. B. (Org.). 1. ed. Turismo Rural. São Paulo: Contexto, 2001. p. 133-150.

RUSCHMANN, D. V. M. Turismo e Planejamento Sustentável: a proteção do meio ambiente. 7. ed. Campinas: Papirus 2001. cap. 3.

SANTOS, M. A Natureza do Espaço: técnica e tempo, razão e emoção. 4. ed. São Paulo: Edusp. 1999. p. 266.

SILVA, J. A. S. Turismo, Crescimento e Desenvolvimento: uma análise urbano-regional baseada em Cluster. 2004, 480f. Tese (Doutorado em Geografia.) - Faculdade de Filosofia, Letras e Ciências Humanas da Universidade de São Paulo. USP, São Paulo.

SILVEIRA, M. A. T. Turismo, Políticas de Ordenamento Territorial e Desenvolvimento. Um foco no Estado do Paraná no Contexto Regional. 2002, 277 f. Tese (Doutorado em Geografia) Faculdade de Filosofia, Letras e Ciências Humanas da Universidade de São Paulo. USP, São Paulo.

SMITH, S. Tourism Analysis. A handbook. 1. ed. New York/London: Longman, 1989. p. 273-302.

WORLD TOURISM ORGANIZATION - WTO. Turismo y Desarrollo Local sostenible: elemento para un debate. In: Noticias Delnet - Centro Internacional de Formación de la OIT. n.24. 2004. Disponible em: <http://www.world-tourism.org >. Acesso em: 11 Oct. 2004

ZACARELLI, S. B. Estratégia e Sucesso nas Empresas. 4. ed. São Paulo: Saraiva. 2004. cap. 13. p. 187-208. 